\title{
Non-destructive bulk analysis of the Buggenum sword by neutron resonance capture analysis and neutron diffraction
}

\author{
Hans Postma · Luc Amkreutz • Alessandro Borella • \\ Martijn Clarijs • Hans Kamermans • Winfried Kockelmann • \\ Anna Paradowska · Peter Schillebeeckx • Dirk Visser
}

Received: 8 October 2009/Published online: 3 December 2009

(C) Akadémiai Kiadó, Budapest, Hungary 2009

\begin{abstract}
Two neutron based techniques, neutron resonance capture analysis (NRCA) and time-of-flight neutrondiffraction (TOF-ND) have been used to determine the elemental composition and structure of a precious and very well preserved all-metal sword from the Bronze Age. This Buggenum sword was on loan from the National Museum of Antiquities (NMA) in Leiden (NL). NRCA and TOF-ND experiments have been carried out at a number of more or less identical positions of the sword. The tin-bronze ratio and the relative amounts of some minor elements ( $\mathrm{Sb}, \mathrm{As}$, $\mathrm{Ag}$, In) have been determined. The results of neutron diffraction measurements showed considerable tin-segregation, and clear indications of hardening on the edges of the blade. In addition, radiographs using Bremsstrahlung revealed the construction of the hilt-blade connection. The work was carried out at the EC Joint Research Centre
\end{abstract}

H. Postma $(\bowtie) \cdot$ M. Clarijs

RD\&M, Faculty of Applied Sciences, Delft University of Technology, Mekelweg 15, 2629 JB Delft, The Netherlands e-mail: postma-bosch@dataweb.nl

\section{Amkreutz}

National Museum of Antiquities, Papengracht 30,

2301 EC Leiden, The Netherlands

A. Borella $\cdot$ P. Schillebeeckx

EC-JRC, Institute of Reference Materials and Measurements

(IRMM), Retieseweg 111, Geel 2440, Belgium

H. Kamermans

Faculty of Archaeology, University of Leiden, Leiden,

The Netherlands

W. Kockelmann - A. Paradowska - D. Visser ISIS Facility, Rutherford and Appleton Laboratory,

Chilton Didcot OX11 0QX, UK
IRMM in Geel (B) and at the ISIS facility of the Rutherford Appleton Laboratory (UK).

Keywords Neutron resonances - Radiography · Non-destructive analysis · Neutron diffraction . Bronze Age

\section{Introduction}

Resonance peaks occurring in cross sections of neutroninduced capture reactions as function of neutron energy can be used to identify and to quantify elements in materials and objects. This is the basis of neutron resonance capture analysis (NRCA), a non-destructive analytical method. Due to the deep penetration of epithermal neutrons in matter, the bulk elemental composition can be determined [1,2]. NRCA has been applied to determine the elemental composition of a precious and very well preserved all-metal sword, which was found near the village Buggenum (NL) during the dredging of a lateral canal of the river Meuse. The owner of the Buggenum sword, the National Museum of Antiquities (NMA) in Leiden (NL), was interested in studying this sword by non-invasive, non-destructive methods. Therefore, NRCA measurements have been performed to determine its elemental composition using the time-of-flight facility GELINA of the Institute of Reference Materials and Measurements (IRMM) in Geel (B). In addition radiographs obtained with Bremsstrahlung produced by the accelerator of this facility revealed details about the connection of the blade and the hilt of the sword.

A series of time-of-flight neutron diffraction experiments was carried out with this object at the ENGIN-X instrument [3], installed at the ISIS facility of the Rutherford-Appleton Laboratory (UK), to obtain information 
about its crystalline structure and microstructure, which are related to its casting and working history of this sword. ENGIN-X makes it possible to carry out diffraction experiments in well-defined volumes near the surface or inside the object. Also this method is non-invasive, nondestructive and therefore suitable for this study. There are no other methods available which are non-destructive and able to give information about bulk properties of artifacts.

Although both methods are based on neutrons, the remaining radioactivity of objects due to neutron capture is negligible after a short waiting period.

In this paper technical aspects of NRCA and TOF-ND together with details of the instrumentation and results of the analyses are discussed. The work reported in this paper was carried out as part of the EU FP6 Ancient Charm project, in which ten scientific institutes and museums collaborate to improve and to develop certain neutronbased analytical and imaging methods for cultural heritage applications.

\section{The Buggenum sword}

The Buggenum sword is one of the richly decorated allmetal (bronze) swords coming from the region of the Upper-Danube and its alpine tributaries [4]. It was dated to the Hallstatt A1 period of the Bronze Age or slightly later [5]. It is in a perfect condition with beautiful decorations on both the hilt and pommel. The sword, shown in Fig. 1, is $68 \mathrm{~cm}$ long and weighs $920 \mathrm{~g}$. In the region where the hilt goes over into the blade there are decorative incised lines and four small circular elements, which look like rivets. Two of them only appear as rivets but the other two seem to be genuine dome-shaped rivets hidden in the line-shaped decoration. No traces of seams (brazing or soldering) could be recognized at the "omega shaped" connection between hilt and blade, or near the pommel. The way the blade and hilt are connected could therefore only be speculated on the basis of what is known from the literature. There is a thick rib in the middle on both sides of the blade of the sword. The blade is slightly sharpened, but apparently it was never used as a weapon because visual examination shows no obvious indications of use. It was therefore concluded that it has been served as a ceremonial object [5]. The results of the measurements reported in this paper may help to clarify its construction and whether it has been made as a functional weapon or not.

\section{Experiments at GELINA}

The basic unit of GELINA is a linear electron accelerator producing very short pulses of electrons with energies up to

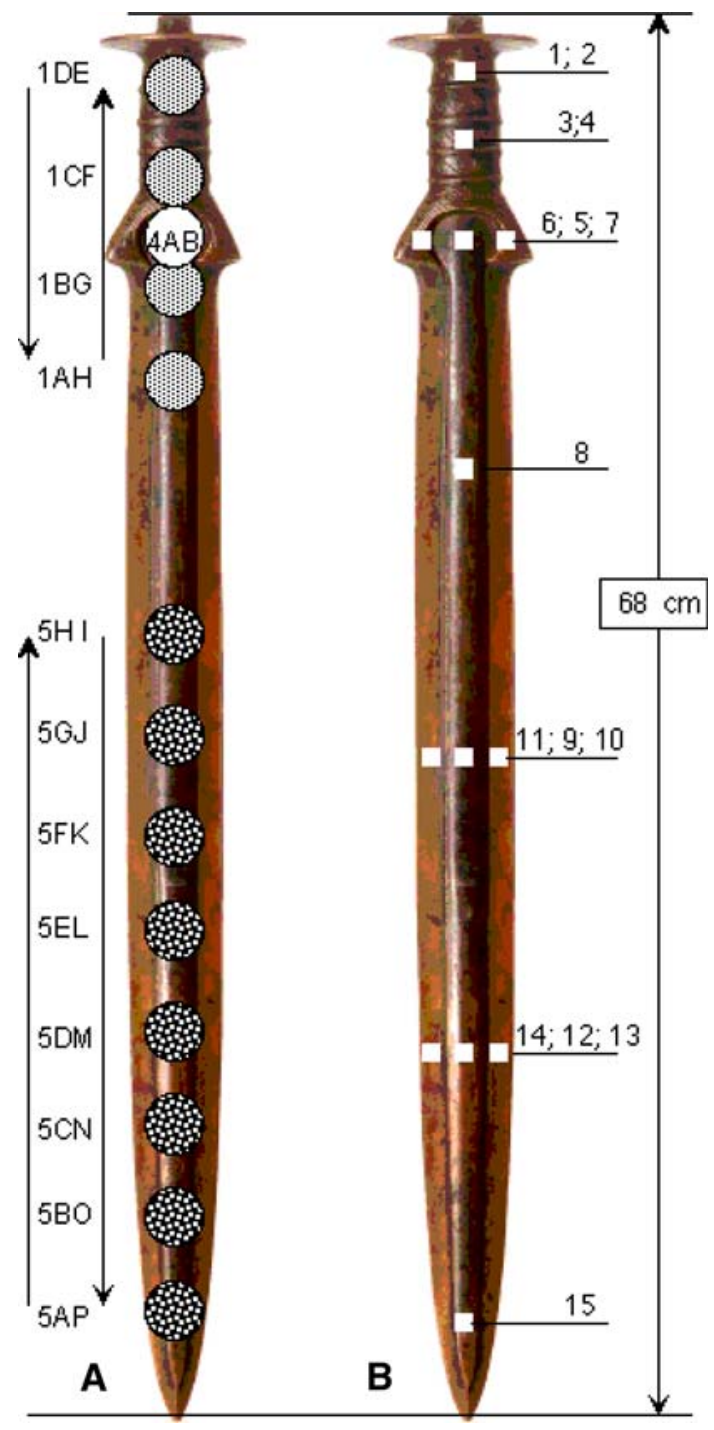

Fig. 1 The left side (a) shows the positions on the Buggenum sword during the NRCA experiments at the GELINA facility in Geel, and the right side (b) shows the analysis positions for the neutron diffraction experiments on ENGIN-X of the ISIS facility of the Rutherford-Appleton Laboratory in Harwell (UK). The photo of the Buggenum sword was provided by Peter-Jan Bomhof, National Museum of Antiquities, Leiden (NL)

$150 \mathrm{MeV}$ and a maximum repetition rate of $800 \mathrm{~Hz}$. Stopping these electrons in a disk of uranium produces Bremsstrahlung, which in turn generates neutrons by photonuclear and fission reactions. The energy distribution of these neutrons has a maximum at around $1 \mathrm{MeV}$. To produce a neutron spectrum in the low energy region, the neutrons are slowed down in two 4-cm thick Be-containers filled with water and positioned just above and below the uranium disk. The beam tubes are viewing these containers. In this way pulsed beams of "white" neutrons are obtained. The energy dependence of the neutron flux in the epithermal region is in good approximation given by $E^{-\alpha}$ with $\alpha \approx 0.9$. Notwithstanding moderation in the water-filled 
Be-containers there is still a very good time resolution to apply the time-of-flight (TOF) technique and to observe resonance structures resulting from neutrons interacting within an object. One can find more details of the GELINA facility in a paper by Mondelaers and Schillebeeckx [6].

Neutron TOF spectra can be obtained by detecting the prompt gamma-radiation emitted after a neutron has been captured in the object. This requires gamma ray detectors with good time resolution and low sensitivity for neutrons. The low neutron sensitivity is important to reduce the impact of neutrons, which are scattered by the object into the detector and its environment. Since scattered neutrons also produce a gamma-ray background in the detector environment its construction should be light and from materials with low neutron capture cross-sections. At GELINA mostly scintillation detectors filled with liquid $\mathrm{C}_{6} \mathrm{D}_{6}$ are used to measure TOF-spectra in the resonance region. They have the required low sensitivity for neutrons and a very good time resolution better than $1 \mathrm{~ns}$. Their rather poor energy resolution for gamma rays is not really a disadvantage since detection of gamma rays is primarily used to create a time signal that a capture event has occurred. This time signal together with a signal from the pulsed electron beam is used to determine the time-of-flight of a neutron creating a capture event. The time-of-flight $(t)$ that a neutron needs to travel a given distance $(L)$ can be used to determine the energy $(E)$ of the neutron creating the capture event. At low energies, that is in the non-relativistic case, the neutron energy is $E=1 / 2 m(L / t)^{2}$ with $m$ being the neutron rest mass.

When the accelerator operates at a relatively high frequency, the influence due to slow neutrons from previous accelerator pulses, that is due to overlap neutrons, can be reduced by inserting a ${ }^{10} \mathrm{~B}$ or $\mathrm{Cd}$ overlap filter in the beam. The overlap energy is determined by the operating frequency and flight path length. A 1-mm thick sheet of natural cadmium is sufficient to remove neutrons with a kinetic energy below about $0.5 \mathrm{eV}$. In case one is interested in the amount of $\mathrm{Cd}$ in an object $\mathrm{a}^{10} \mathrm{~B}$ filter can be used. The energy dependence of the ${ }^{10} \mathrm{~B}(n, \alpha)$ reaction crosssection in the epithermal region behaves as $E^{-0.5}$ and is 3837 barn for thermal neutrons of $0.0254 \mathrm{eV}$. The use of an overlap filter has the additional advantage that thermal neutrons, which are not used in NRCA measurements, are removed and therefore the activation of samples is largely reduced. Since the intense Bremsstrahlung flash may block the detector during several $\mu \mathrm{s}, \mathrm{a} \mathrm{Pb}, \mathrm{Bi}$ or S-filter is placed in the beam. The optimum type and thickness of the filters depend on the application.

Measurements have been performed at two beams with flight-path lengths of 12.38 and $28.88 \mathrm{~m}$, making angles of respectively $108^{\circ}$ and $90^{\circ}$ with the direction of the electron beam.
At the $12.38 \mathrm{~m}$ station a new system of ten large $\mathrm{C}_{6} \mathrm{D}_{6}$ scintillation detectors [7] arranged in a dodecaeder configuration has been installed. To determine the elemental composition at different places of the object, the sword was placed in an automated scanning system, which was linked to the data acquisition system. The moderated neutron beam was collimated by a series of $\mathrm{Pb}, \mathrm{Cu}, \mathrm{B}_{4} \mathrm{C}$ mixed with epoxy resin, and lithium carbonate collimators. The resulting profile, with a $19 \mathrm{~mm}$ FWHM at the sample position, is shown in Fig. 2. In this figure the response of the gamma-ray detection system for the 21.06-eV resonance of ${ }^{182} \mathrm{~W}$ obtained with a $2-\mathrm{mm}$ diameter ${ }^{\text {nat }} \mathrm{W}$ sample is plotted as a function of the position of the sample. The experimental response is compared with the relative neutron intensity as obtained from Monte Carlo simulations using the MCNP code, version 4C3 [8]. The good agreement between the experimental and simulated profile confirms the quality of the collimation system.

With the Buggenum sword at the $12.38 \mathrm{~m}$ measurement station, five different runs were carried out. An overview of the operating conditions for the different runs, Bug1 to 5 , is given in Table 1. The first run (Bug1) concerned four positions, two on the hilt and two on the top section of the blade near the hilt. At each position data were collected during $1 \mathrm{~h}$. The distance between consecutive positions was $5 \mathrm{~cm}$. These positions are indicated as $1 \mathrm{AH}, 1 \mathrm{BG}$, 1CF, and 1DE in Fig. 1a. With the sword moving forwards and backwards each position was measured twice and the data of each pair was summed. Run Bug3 with a strip of tungsten positioned at the "bottom of the omega" was carried out to define the positions on the sword with respect to the neutron beam. In run Bug4 the beam spot was centred onto the "omega-shaped" area at the connection of the blade and hilt. This position is indicated as $4 \mathrm{AB}$ in Fig. 1a. In run Bug5 TOF-spectra were obtained at eight positions on the blade again in steps of $5 \mathrm{~cm}$ and in two directions.

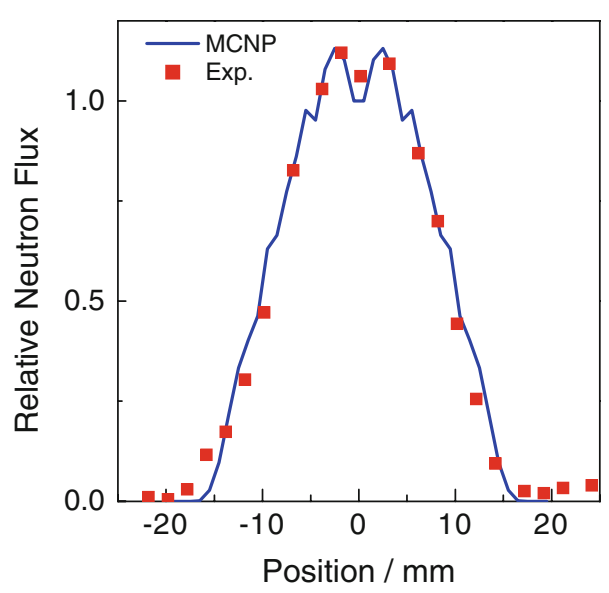

Fig. 2 Profile of beam 5 at the $12.38 \mathrm{~m}$ station of GELINA 
Table 1 Experimental details of NRCA experiments performed at GELINA

\begin{tabular}{lllll}
\hline Id & Flight path $(\mathrm{m})$ & Overlap filter & $\gamma$-ray beam filter & Comments \\
\hline Bug1 & 12.38 & ${ }^{\text {nat }} \mathrm{Cd}(1 \mathrm{~mm})$ & $\mathrm{Bi}(1.5 \mathrm{~cm})$ & Position: 1AH-1DE \\
Bug2 & 12.38 & ${ }^{10} \mathrm{~B}\left(4.2 \times 10^{-3} \mathrm{at} / \mathrm{b}\right)$ & $\mathrm{Pb}(1.5 \mathrm{~cm})$ & Position: same \\
Bug3 & 12.38 & ${ }^{\text {nat }} \mathrm{Cd}(1 \mathrm{~mm})$ & $\mathrm{Bi}(1.5 \mathrm{~cm})$ & Position calibration \\
Bug4 & 12.38 & ${ }^{n a t} \mathrm{Cd}(1 \mathrm{~mm})$ & $\mathrm{Bi}(1.5 \mathrm{~cm})$ & Position: 4AB \\
Bug5 & 12.38 & ${ }^{\text {nat }} \mathrm{Cd}(1 \mathrm{~mm})$ & $\mathrm{Bi}(1.5 \mathrm{~cm})$ & Position: 5AP-5HI \\
Bug6 & 28.88 & ${ }^{10} \mathrm{~B}\left(1.29 \times 10^{-2} \mathrm{at} / \mathrm{b}\right)$ & $\mathrm{S}(8 \mathrm{~cm})$ & Hilt \\
Bug7 & 28.88 & ${ }^{10} \mathrm{~B}\left(1.29 \times 10^{-2} \mathrm{at} / \mathrm{b}\right)$ & $\mathrm{S}(8 \mathrm{~cm})$ & Blade \\
\hline
\end{tabular}

The positions are indicated as $5 \mathrm{AP}, 5 \mathrm{BO}, 5 \mathrm{CN}, 5 \mathrm{DM}, 5 \mathrm{EL}$, 5FK, 5GJ, and 5HI in Fig. 1a.

To investigate the presence of elements with resonance structures in the high-energy region, measurements at a $28.88 \mathrm{~m}$ flight path, resulting in a better energy resolution, have been carried out. These experiments have been performed with a $7.5 \mathrm{~cm}$ beam diameter at the sample position using two $\mathrm{C}_{6} \mathrm{D}_{6}$ detectors. Due to the lower flux longer measurement times were required, and therefore these experiments were carried out at only two positions on the object.

By removing the ${ }^{\text {nat }} \mathrm{S}$-filter from the beam this measurement station has also been used to make radiographs of the hilt and the connection between the blade and the hilt.

\section{Radiographs of the hilt}

Radiographs of the hilt were made at the $28.88 \mathrm{~m}$ station by placing a film downstream directly behind the sword. With a beam diameter of $7.5 \mathrm{~cm}$ two photos were needed to cover the hilt, one for the upper part of the hilt, and a second one to cover the lower part including the "omega" region where blade and hilt are connected. The exposure times were about $2 \mathrm{~h}$. These radiographs are combined in Fig. 3, and together with the drawing, reveal how blade and hilt are connected. Clearly the hilt is hollow and actually fairly thin-walled with its external ring-like ridges well visible. The blade has apparently a tongue reaching far inside the hilt where it ends at the wall roughly between the second and third external rings seen from the pommel. With the hilt slightly tapered, the tongue/hilt construction functions as a key. In this position the blade is attached to the hilt with the aid of two rivets, which are visible on the radiographic photo. In the decoration of the hilt there are two small, incised circles as fake rivets.

\section{NRCA analysis}

Figure 4 shows the TOF-spectrum obtained by summing the individual runs of Bug5, with a total measuring time of

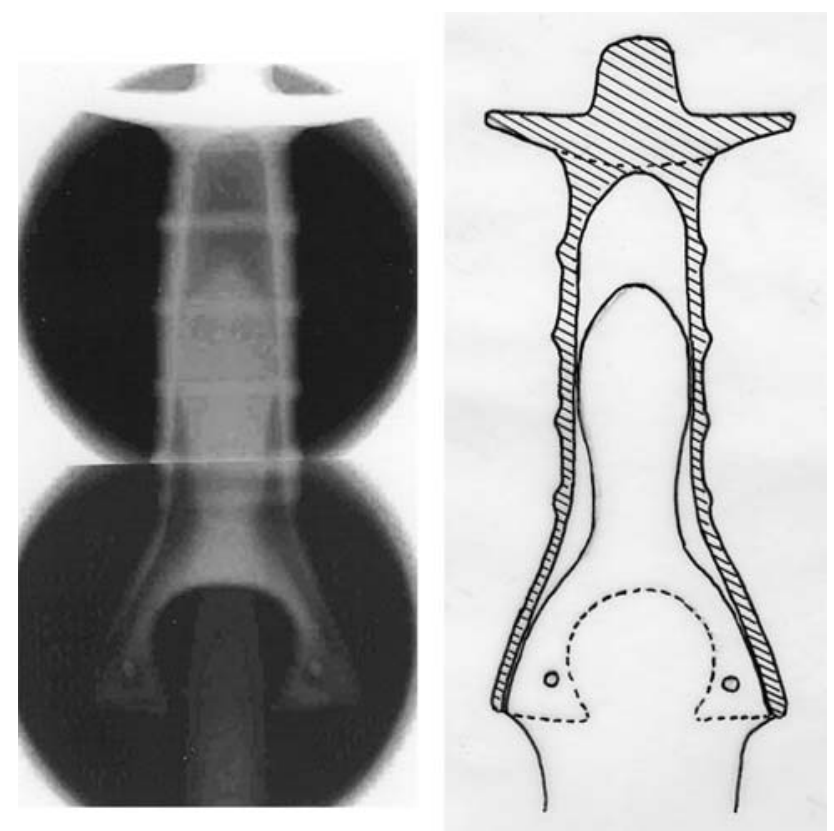

Fig. 3 Hilt of the Buggenum sword: Radiographic picture and drawing showing the way blade and hilt are connected

$16 \mathrm{~h}$. Of the many resonance peaks in this spectrum only the most important ones for the analysis are indicated. Since this spectrum has the best counting statistics it was used to determine the overall elemental composition of the blade including trace elements, which could not be detected from the separate runs at different positions. The double ratio method $[1,2]$ was used for the data analysis. This method relies on ratios of observed resonance areas and the use of calibration samples of known elemental compositions.

Applying the double ratio method the total number of counts integrated over a resonance is determined. The simplest approach to obtain the area of a resonance peak is by summing up all counts under the peak and subtracting the underlying background. This is not always evident especially in case of overlapping resonances and for resonance peaks which are affected by the contribution from neutrons which are scattered in the sample prior to being captured. This contribution creates an additional structure 
Fig. 4 TOF-spectrum of the Bug5 sum-run with two inserts showing details of the spectrum

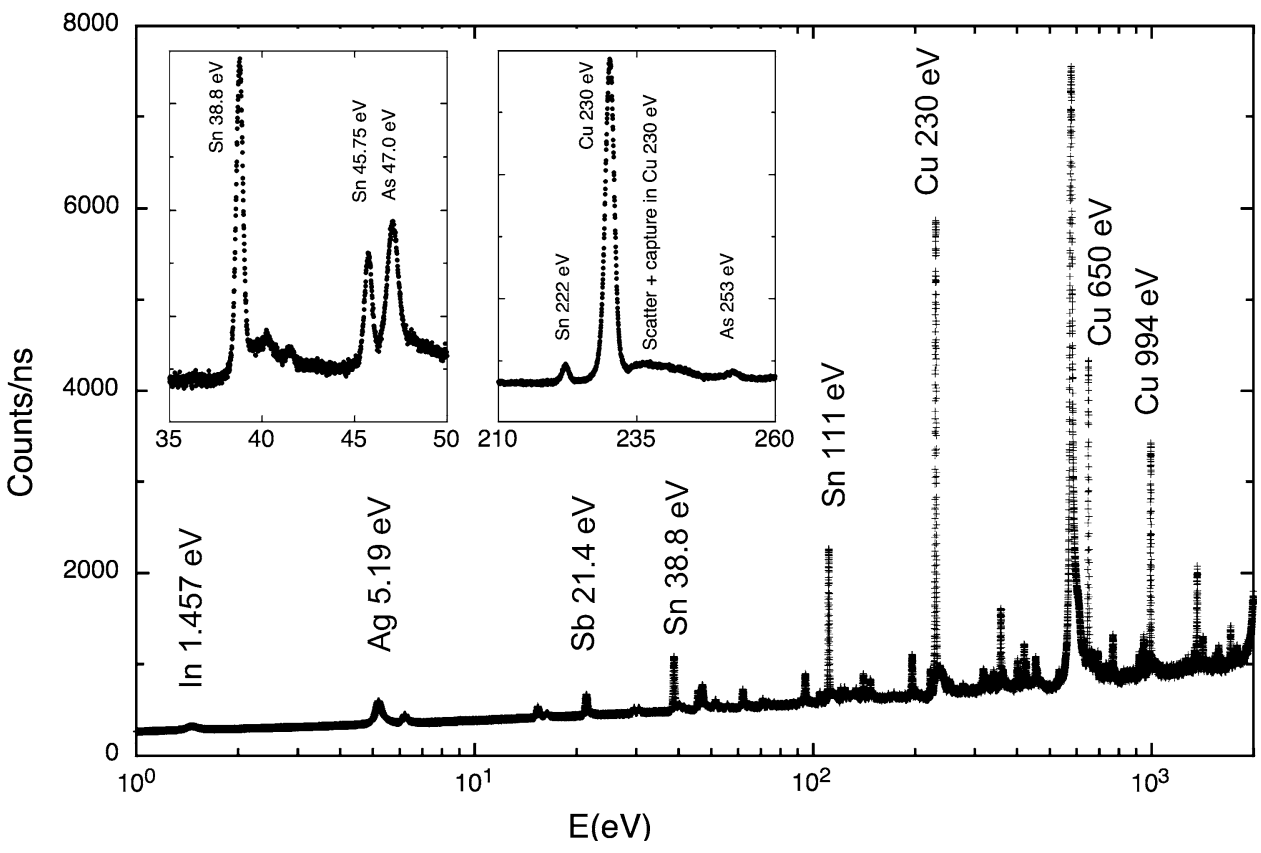

on the low TOF (high energy) side of the peak. One of the two inserts in Fig. 4 shows the contribution of such events for the $230-\mathrm{eV}$ resonance of ${ }^{65} \mathrm{Cu}$. Since the double ratio method is based on the contribution of neutron induced capture events, without neutrons being first scattered inside the sample, this structure has to be subtracted. For the 230$\mathrm{eV}$ resonance of ${ }^{65} \mathrm{Cu}$ only a small fraction of the scattercapture events is underneath the resonance peak. The contribution of such events can be subtracted by a parametric fitting with reasonable accuracy. However, in cases of low energy resonances, for instance the $5.19-\mathrm{eV}$ resonance of $\mathrm{Ag}$ and the $1.457-\mathrm{eV}$ resonance of ${ }^{115} \mathrm{In}$, a large fraction of the scatter-capture events is underneath the resonance peak and then parametric fitting becomes difficult if not impossible. Hence some care is needed to determine the net capture areas of resonance peaks and in some cases it is better to restrict the number of resonances of an element in the analysis.

Applying the double ratio method the weight ratio of two elements $X$ and $Y$ in an object is given by:

$\frac{W_{X}}{W_{Y}}=K_{\mu, \lambda}^{\mathrm{cal}} \frac{F_{\lambda} N_{\mu}}{F_{\mu} N_{\lambda}}$.

$K_{\mu, \lambda}^{\mathrm{cal}}$ is a calibration constant and $N_{\mu}$ and $N_{\lambda}$ are the resonance areas of the capture peaks of the resonances $\mu$ and $\lambda$ of the elements $X$ and $Y$, and $F_{\lambda}$ and $F_{\mu}$ are their selfshielding factors. The self-shielding factor accounts for the reduction of the neutron beam traversing the sample and depends on the macroscopic total cross-section around the resonance energy. The averaged resonance self-shielding factor $F\left(E_{\lambda}\right)$ for a single resonance of element $X$ with energy $E_{\lambda}$ can be calculated on the basis of its Dopplerbroadened total cross-section $\sigma_{\mathrm{tot}}^{\mathrm{D}}(E)$ :

$F\left(E_{\lambda}\right)=\frac{\int_{\text {res }} \varphi(E)\left(1-\exp \left(-n_{X} \sigma_{\text {tot }}^{\mathrm{D}}(E)\right)\right)}{\int_{\text {res }} \varphi(E) n_{X} \sigma_{\text {tot }}^{\mathrm{D}}(E)}$.

Here $\varphi(E)$ is the energy dependence of the incoming neutron flux and $n_{X}$ represents the areal density, that is, number of atoms per unit area of element $X$. The calibration factor $K_{\mu, \lambda}^{\mathrm{cal}}$ is obtained from measurements carried out under the same experimental conditions using calibration samples with known elemental compositions and thicknesses:

$K_{\mu, \lambda}^{\mathrm{cal}}=\left(\frac{F_{\mu} N_{\lambda} W_{X}}{F_{\lambda} N_{\mu} W_{Y}}\right)_{\mathrm{cal}}$.

Consequently, the weight ratio of two elements in an object is obtained from the double ratio of peak areas of two resonances, one for each element, multiplied by the weight ratio of the calibration sample and corrected for self-shielding factors. In this double ratio method the detection efficiencies as well as the energy dependence of the incoming neutron flux cancel to a high degree.

The influence of self-shielding on resonance peak intensities depends on the resonance strength. This feature makes it possible to derive the areal density of elements if two or more resonances for each element with different strengths are observed. In the case of a bronze object, such as the Buggenum sword, the $\mathrm{Cu}$ resonances at 230, 650, and $994 \mathrm{eV}$ and the $\mathrm{Sn}$ resonances at 38.8, 45.75 and $111.2 \mathrm{eV}$ can be used. With these resonances nine pairs of resonance areas can be defined which are affected in 


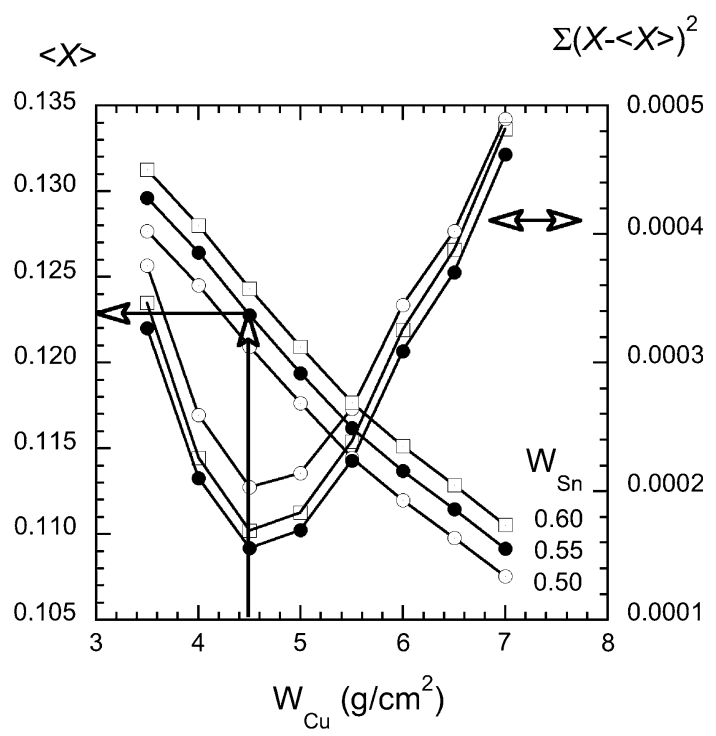

Fig. 5 Minimum $\chi^{2}$-method used to determine the areal densities of copper and tin simultaneously and thus the $\mathrm{Sn} / \mathrm{Cu}$ weight ratio

different ways by self-shielding. Without correcting for self-shielding the deduced $\mathrm{Cu} / \mathrm{Sn}$ weight ratios of an object will not be consistent. A minimum $\chi^{2}$-method can be applied to determine the effective $\mathrm{Cu}$ and $\mathrm{Sn}$ areal densities such that consistent weight ratios $R=W_{\mathrm{Cu}} / W_{\mathrm{Sn}}$ are obtained. Figure 5 illustrates how the quantity $\Sigma(R-$ $\langle R\rangle)^{2}$, with $\langle R\rangle$ the average value resulting from the ratios of resonance areas, is minimized by changing the areal density of $\mathrm{Cu}$ and $\mathrm{Sn}$.

For all measurements performed with the Buggenum sword $\mathrm{Sn} / \mathrm{Cu}$ weight ratios have been deduced together with the weight ratios of the minor elements $\mathrm{Sb}, \mathrm{As}, \mathrm{Ag}$ and In with respect to $\mathrm{Cu}$. The results are summarised in Table 2. All weight ratios in Table 2, except the $\mathrm{In} / \mathrm{Cu}$ ratio, have been derived from resonance areas corrected for the scatter-capture contribution. In the last column the areal density at different positions is given.

Figure 6 shows the $\mathrm{Sn} / \mathrm{Cu}$ weight ratios as a function of the distance from the tip of the sword together with the deduced areal weights. The ratios of the other elements ( $\mathrm{Sb}, \mathrm{As}, \mathrm{Ag}$ and $\mathrm{In}$ ) with respect to $\mathrm{Cu}$ are given in Fig. 7.

The relative amounts of $\mathrm{Co}$ and $\mathrm{Zn}$ of the blade were obtained from the sum-run of Bug5. Although partly overlapped by two weak resonances of $\mathrm{Sb}$ and $\mathrm{Ag}$, it was possible to determine the area of the broad Co-resonance at $132 \mathrm{eV}$. The $\mathrm{Zn}$-resonance at $282 \mathrm{eV}$ showed up as a weak peak in the sum-run of Bug5. The contributions of Co and $\mathrm{Zn}$ were taken into account in the calculation of the overall elemental compositions for the blade; see Table 3.

For the hilt the amounts of the main and minor elements ( $\mathrm{Sb}, \mathrm{As}, \mathrm{Ag}$ and In) were obtained from the measurement at position $1 \mathrm{DE}$ and for $\mathrm{Co}$ and $\mathrm{Zn}$ the measurement at the longer flight path of $28.878 \mathrm{~m}$ was used. These results are
Table 2 Weight ratios of $\mathrm{Sn}$ and the four minor element $\mathrm{Sb}, \mathrm{As}, \mathrm{Ag}$ and $\mathrm{In}$ with respect to $\mathrm{Cu}$ on ten positions of the blade, two positions of the hilt and one at the connection of hilt to blade

\begin{tabular}{ccccccc}
\hline Subrun & $\mathrm{Sn} / \mathrm{Cu}$ & $\mathrm{Sb} / \mathrm{Cu}$ & $\mathrm{As} / \mathrm{Cu}$ & $\mathrm{Ag} / \mathrm{Cu}$ & $\mathrm{In} / \mathrm{Cu}^{\mathrm{a}}$ & $\mathrm{g} / \mathrm{cm}^{2}$ \\
\hline Bug5 & & & & & & \\
5-AP & 0.1265 & 0.00189 & 0.00094 & 0.00067 & 0.000129 & 4.17 \\
5-BO & 0.1250 & 0.00199 & 0.00092 & 0.00063 & 0.000122 & 4.06 \\
5-CN & 0.1266 & 0.00194 & 0.00090 & 0.00065 & 0.000121 & 4.84 \\
5-DM & 0.1264 & 0.00189 & 0.00087 & 0.00064 & 0.000123 & 4.51 \\
5-EL & 0.1245 & 0.00205 & 0.00089 & 0.00065 & 0.000135 & 5.07 \\
5-FK & 0.1270 & 0.00190 & 0.00090 & 0.00062 & 0.000125 & 5.08 \\
5-GJ & 0.1262 & 0.00195 & 0.00094 & 0.00063 & 0.000129 & 5.07 \\
5-HI & 0.1280 & 0.00200 & 0.00094 & 0.00063 & 0.000132 & 5.08 \\
Bug1 & & & & & & \\
1-AH & 0.1280 & 0.00188 & 0.00086 & 0.00061 & 0.000130 & 5.88 \\
1-BG & 0.1290 & 0.00188 & 0.00088 & 0.00061 & 0.000135 & 6.23 \\
1-CF & 0.142 & 0.00203 & 0.00106 & 0.00064 & 0.000123 & 8.88 \\
1-DE & 0.151 & 0.00235 & 0.00123 & 0.00053 & 0.000115 & 7.45 \\
Bug4 & & & & & & \\
4-AB & 0.129 & 0.00187 & 0.00086 & 0.00064 & 0.000136 & 6.79 \\
\hline
\end{tabular}

The last column gives the areal density at these positions

${ }^{\text {a }}$ Scatter-capture events are not subtracted

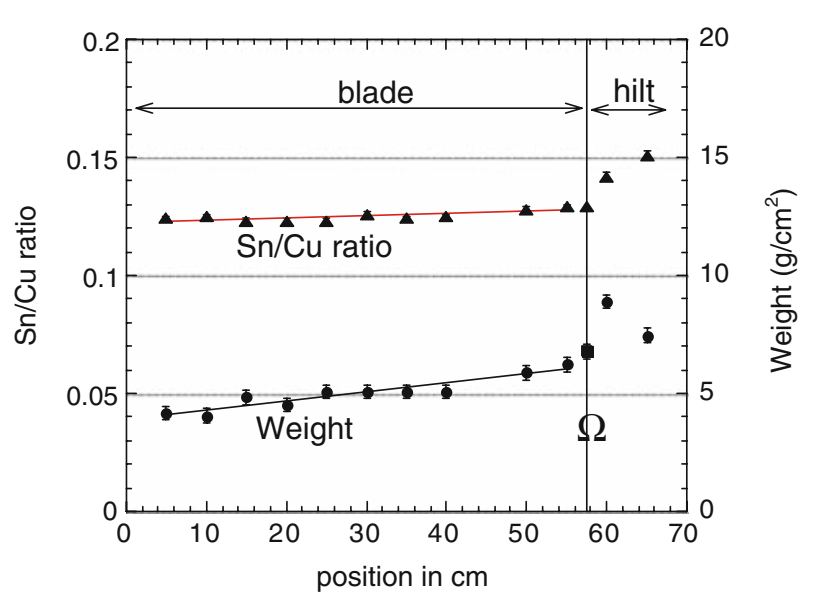

Fig. $6 \mathrm{Sn} / \mathrm{Cu}$ weight ratios determined at 13 positions along the sword and the total areal densities at these positions in $\mathrm{g} / \mathrm{cm}^{2}$

quoted in Table 3. In the run with the hilt at the longer flight path there is a weak indication of nickel at its 2255$\mathrm{eV}$ resonance giving 0.0045 as an upper limit for the $\mathrm{Ni} / \mathrm{Cu}$ ratio. There were no indications for $\mathrm{Fe}$ at its strongest resonance at $1149 \mathrm{eV}$, for $\mathrm{Pb}$ at its resonances of 3063 and $3357 \mathrm{eV}$, and for $\mathrm{Bi}$ at its resonances of 800 and $2310 \mathrm{eV}$. Upper limits for the $\mathrm{Fe} / \mathrm{Cu}, \mathrm{Pb} / \mathrm{Cu}$ and $\mathrm{Bi} / \mathrm{Cu}$ ratios were estimated to be $0.0005,0.012$ and 0.013 respectively. A run at the longer flight path with the blade was too short to give a similar result. Upper limits for the weight ratios of $\mathrm{Fe} / \mathrm{Cu}$ and $\mathrm{Pb} / \mathrm{Cu}$ of the blade respectively 0.0010 and 0.027 were obtained from the sum run of Bug5. 


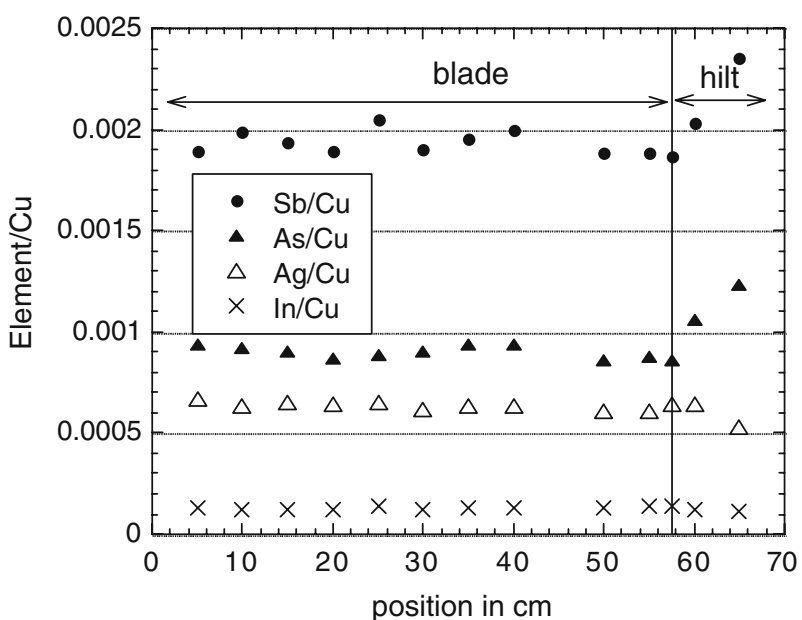

Fig. 7 Weight ratios of the four elements $\mathrm{Sb}, \mathrm{As}, \mathrm{Ag}$ and In with respect to copper plotted for 13 positions on the Buggenum sword

Table 3 Elemental composition of the blade and hilt

\begin{tabular}{lll}
\hline Element & wt\% (blade) & wt\% (hilt) \\
\hline $\mathrm{Cu}$ & $88.44 \pm 0.15$ & $86.40 \pm 0.15$ \\
$\mathrm{Sn}$ & $11.06 \pm 0.14$ & $13.05 \pm 0.15$ \\
$\mathrm{Sb}$ & $0.172 \pm 0.009$ & $0.203 \pm 0.017$ \\
$\mathrm{As}$ & $0.080 \pm 0.009$ & $0.106 \pm 0.017$ \\
$\mathrm{Ag}$ & $0.056 \pm 0.004$ & $0.046 \pm 0.007$ \\
$\mathrm{In}$ & $0.011 \pm 0.001$ & $0.010 \pm 0.002$ \\
$\mathrm{Co}$ & $0.012 \pm 0.003$ & $0.004 \pm 0.001$ \\
$\mathrm{Zn}$ & $0.177 \pm 0.053$ & $0.181 \pm 0.026$ \\
\hline
\end{tabular}

The results of the NRCA measurements at the ten positions (5AP to 5HI, $1 \mathrm{AH}$ and $1 \mathrm{BG}$ ) on the blade as quoted in Table 1 and plotted in Figs. 5 and 6 show that the $\mathrm{Sn} / \mathrm{Cu}$ weight ratio varies very little and that the relative amounts of the four minor elements do not vary over the length of the blade. The errors of the $\mathrm{Sn} / \mathrm{Cu}$ weight ratios are about 0.0020 mainly due to aspects of the analysis and very little due to statistics. The overall elemental composition determined from the sum of the Bug5 sub-runs as quoted in Table 3 is $88.44 \mathrm{wt} \% \mathrm{Cu}$ and $11.06 \mathrm{wt} \% \mathrm{Sn}$. The remaining $0.50 \mathrm{wt} \%$ is due to the presence of the minor elements $\mathrm{Sb}, \mathrm{As}, \mathrm{Ag}$, In, $\mathrm{Co}$ and $\mathrm{Zn}$. The composition of the hilt as extracted from the measurement at position 1DE is: $86.40 \mathrm{wt} \% \mathrm{Cu}, 13.05 \mathrm{wt} \%$ $\mathrm{Sn}$ and $0.55 \mathrm{wt} \%$ for the minor elements. Thus the hilt has clearly a higher tin content compared to the blade. Also the relative amounts of $\mathrm{Sb}$ and As are slightly larger for the hilt, but the $\mathrm{Ag} / \mathrm{Cu}$ and $\mathrm{In} / \mathrm{Cu}$ weight ratios are the same in the hilt and the blade. Therefore, one can conclude that the hilt and blade were cast separately, with different bronze compositions. Considering the width of the beam (19 mm FWHM), the $\mathrm{Sn}$ content of $11.82 \mathrm{wt} \%$ at $4 \mathrm{AB}$ concerns mainly the blade inside the "omega" region, that is, at most a very small part of the hilt is hit by the edge of the beam in this measurement.

The effective areal density increases from $4.17 \mathrm{~g} / \mathrm{cm}^{2}$ at the tip of the blade to $6.23 \mathrm{~g} / \mathrm{cm}^{2}$ on the hilt. The largest value, $8.88 \mathrm{~g} / \mathrm{cm}^{2}$, observed at position $1 \mathrm{CF}$, is due to the fact that the blade is inserted into the hilt. This is in agreement with the radiographic picture; see Fig. 3. Comparing with the locations at $1 \mathrm{DE}$ and $5 \mathrm{HI}$, the $\mathrm{Sn} / \mathrm{Cu}$ weight ratio at position $1 \mathrm{CF}$ is clearly in between those values obtained from the blade and the hilt. In fact the three $\mathrm{Sn} / \mathrm{Cu}$ values at $1 \mathrm{CF}, 1 \mathrm{DE}$ and $1 \mathrm{HI}$ suggest that the thickness of the tongue is slightly larger than the wall thickness of the hilt.

The amount of indium of about $110 \mathrm{ppm}$ is the largest amount found so far by NRCA in bronze artefacts. The occurrence of Co may be related to minerals from the Alpine region. The amounts of $\mathrm{Zn}$ in the blade and hilt are quite normal, that is, $\mathrm{Zn}$ occurs often in ancient bronze objects in amounts of a fraction of one per cent.

As a general statement, this section is concluded by stating that the obtained composition of this tin-bronze and its minor elements $(\mathrm{Sb}, \mathrm{As}, \mathrm{Ag}, \mathrm{Co}$ ) is of interest for a comparison with other Bronze Age objects (notably swords) from the Upper-Danuba region and tributaries from the North Alps. But this will be done in another, archaeological paper.

\section{TOF-neutron diffraction}

Time-of-flight neutron diffraction (TOF-ND) measurements provide information on the crystalline phase composition of the alloy, the microstructure, strains and crystallographic texture, all of which can be related to the casting and working conditions. If corrosion and secondary phases are present, they can be detected as well. It should be pointed out that TOF-ND, like NRCA, is a bulk analysis method and rather insensitive to surface effects. Assuming that one is dealing with a tin-bronze the apparent $\mathrm{Sn} / \mathrm{Cu}$ ratio can be estimated with TOF-ND from the change of the lattice parameter of the copper alloy. The effect of dissolution of minor elements into the copper lattice can be estimated, by taking into account their concentrations obtained from NRCA.

\section{Experimental details of the ND measurements}

TOF-ND measurements were carried out on the Buggenum sword at the ISIS facility using the engineering diffractometer, ENGIN-X [9], which views a cold liquid $\mathrm{CH}_{4}$ moderator $(110 \mathrm{~K})$ of the pulsed spallation source of the first station of ISIS. Neutrons are produced by stopping 
$800-\mathrm{MeV}$ protons $(160 \mu \mathrm{A})$ in a tungsten/tantalum target with a repetition rate of $50 \mathrm{~Hz}$. The maximum of the flux distribution is around a neutron wavelength of $2 \AA$. The sample position is at $50.0 \mathrm{~m}$ from the moderator. The instrument uses a $33.5 \mathrm{~m}$ long curved super-mirror guide followed by a $10.5 \mathrm{~m}$ long straight guide ending $1.5 \mathrm{~m}$ in front of the sample position. For the measurements on the Buggenum sword, the instrument was operated in an effective $25 \mathrm{~Hz}$ frequency running, using two sets of counter-rotating disk choppers to avoid frame overlap. The corresponding measurement frame was $40 \mathrm{~ms}$ between two successive neutron pulses. The time delay of the chopper openings with respect to the neutron generation at "timezero" determines the neutron wavelength band that can pass through to the sample, and thus determines the associated dspacing range. This time delay was set for a d-spacing range from 1.3 to $3.0 \AA$, to include the characteristic Bragg peak positions of the relevant crystallographic phases.

Scattered neutrons are recorded in two $90^{\circ}$-detector banks, on either side of the sample position at a distance of $1.5 \mathrm{~m}$ from the sample. Each detector bank is composed of $1200 \mathrm{ZnS} /{ }^{6} \mathrm{Li}$ scintillator elements. The detectors measure the TOF of each detected neutron, i.e. the time that passes from the generation of the neutron until its capture in the detector. The interesting aspect of ENGIN-X is, that one can define a small measurement volume (gauge volume) inside the sample as small as a few cubic millimetres. This is achieved by collimating the incident beam (width $\times$ height), and by using a radial collimator in front of the detectors to accept only neutrons from a certain depth along the incident beam direction (Fig. 8). Hence the diffraction pattern only contains neutrons scattered from the gauge volume, which can be fully immersed in the sample or which can be set to measure on the surface of a sample. The sample can be systematically scanned in front of the neutron beam, which means that the gauge volume is scanned through the sample, for example along the blade or into the depth of the sword.

For the TOF-ND measurement presented in this paper the gauge volume was $(4 \times 10) \times 4 \mathrm{~mm}^{3}$, that is, an incident neutron beam of $4 \times 10 \mathrm{~mm}^{2}$ and a $4 \mathrm{~mm}$ opening of the radial collimator. Fifteen analysis points were chosen (see Fig. 1b), inside the hilt (1-4), on the rivets (6, $7)$, inside the mid-rib of the blade $(5,8,9,12,15)$, and on the edge of the blade $(10,11,13,14)$. The collection time per point was about $30 \mathrm{~min}$. An aluminium frame was used to hold the object securely during the measurements. For effective alignment of the object a laser point cloud model, and from that a meshed model, of the outer dimensions of the sword was created using a robotic laser arm. The virtual laboratory software SScanSS [10] was used to select the analysis points inside the sword and to simulate the movements of the object on the instrument. Mounted on top of the moving system on ENGIN-X, the object was aligned by scanning several fiducial (marker) points on the aluminium frame with a laser touch probe.

\section{Analysis of the diffraction data}

The TOF data were normalised by the incoming flux distribution. Two diffraction patterns, one for each $90^{\circ}$ detector bank, were generated from the TOF data, and simultaneously analysed by the Rietveld method with the General Structure Analysis System (GSAS) [11]. The data show considerable Sn-segregation, which is visible as broad structured alpha-bronze peaks. Therefore a series of up to seven alpha-bronze phases were considered in the structure model. The crystallographic space group (SG) for the alpha-phase is $F m-3 m$ with a lattice parameter in a range of $a=3.67$ and $a=3.70 \AA$. The lattice constant depends on the addition of alloying elements such as $\mathrm{Sn}$, $\mathrm{Zn}, \mathrm{Sb}$, and As. A Pb-phase (SG space group Fm-3m, $a=4.9493 \AA$ ) was included. Pb does not dissolve into the copper lattice, and can therefore be observed as a separate phase with a characteristic Bragg peak at $2.86 \AA$. Diffraction peaks of a high-tin delta-phase $\mathrm{Cu}_{31} \mathrm{Sn}_{8}$ with $32.6 \mathrm{wt} \%$ Sn (SG: $F-43 m, a=18.002 \AA$ ) were observed in many patterns of the Buggenum sword. The delta-phase has its largest Bragg peak overlapping with the (111) alpha-phase peaks at a d-spacing of $2.11 \AA$, but has weaker characteristic Bragg peaks at 2.40 and $2.60 \AA$. CuS (SG: $P 6_{3} / m m c, a=3.792 \AA, c=16.342 \AA$ ) was also included which has its dominant peak at $2.82 \AA$, as $\mathrm{CuS}$ was found in similar Bronze Age bronze swords [12]. Figure 9 shows examples of Rietveld fits of ENGIN-X data of two analysis points.

From the lattice parameters of the alpha-bronze, Sncontents were estimated according to Vegard's rule [13], however in practice using a calibration curve for binary $\mathrm{Cu}_{1-x} \mathrm{Sn}_{x}$ [14]. From the set of alpha-phases, the average tin content was calculated for each of the 15 analysis points. The variance (spread) of the Sn-distribution in the alpha-phase was determined. This variance is related to diffraction peak broadening, and gives a quantitative measure of the degree of Sn segregation. The total tin content for each analysis point was calculated by summing the contributions from the alpha-phases and the deltaphase. The estimated systematic error of the Sn-content is typically $0.5 \mathrm{wt} \%$ taking into account the alignment error of the object on the instrument, the estimated standard deviation of the lattice parameters $(0.0001 \AA)$, the uncertainties of the calibration curve [14], and the estimated standard deviation of the delta bronze fraction (typically $0.4 \mathrm{wt} \%$ ). Delta phase fractions of about $0.5 \mathrm{wt} \%$ are at the limit of detection. 
Fig. 8 Schematic lay-out of ENGIN-X. The gauge volume $(4 \times 10) \times 4 \mathrm{~mm}^{3}$ is defined by the size of the incoming beam $(4 \times 10 \mathrm{~mm}$, widths $\times$ height $)$ and by the radial detector in front of the detectors

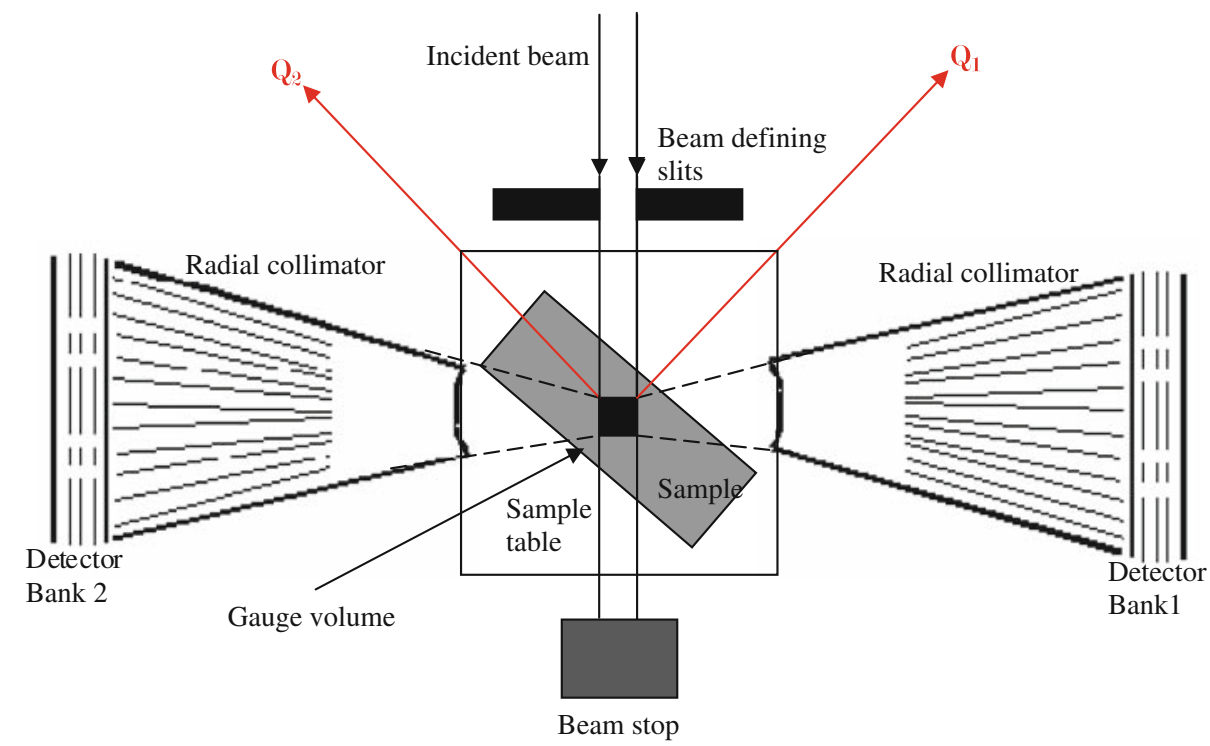

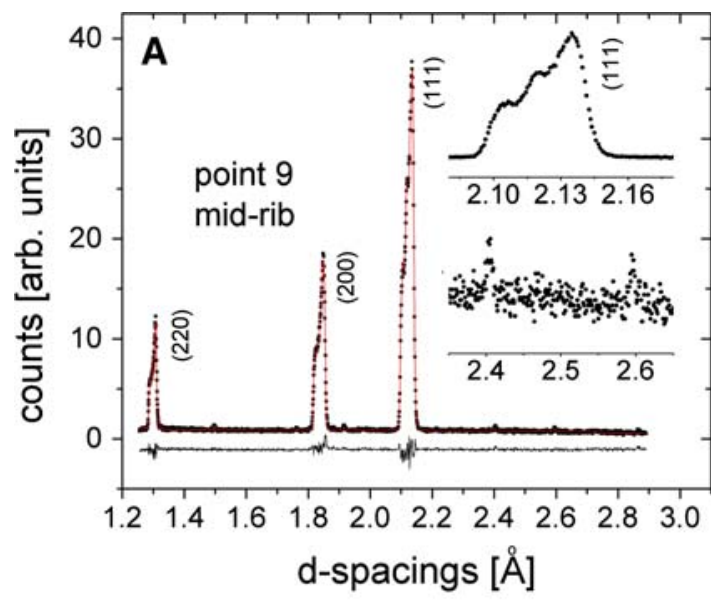

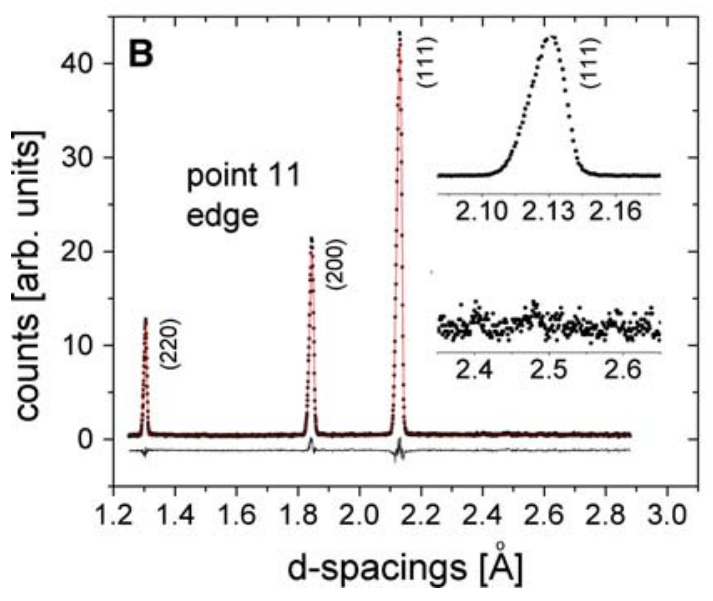

Fig. 9 Fitted diffraction data from ENGIN-X. a Analysis point 9 represents the case of a highly tin-segregated dentritic alloy. Structured alpha peaks and small delta-phase peaks are visible in the inserts; $\mathbf{b}$ Analysis point 11 represents the case of a homogenized bronze, exhibiting much sharper alpha-phase alloy peaks and insignificant delta-phase contributions
$\mathrm{Pb}$ and $\mathrm{CuS}$ Bragg peaks were not observed. The Rietveld refinement allows to estimate an upper limit for the presence of the $\mathrm{Pb}$ phase in the sample, based on the given counting statistics, which is $0.5 \mathrm{wt} \%$. In other words, for a $\mathrm{Pb}$ fraction of more than $0.5 \mathrm{wt} \%$, Bragg peaks would need to be observed above the neutron background noise.

Table 4 contains the phase analysis results of the neutron diffraction data for the 15 positions on the sword (see Fig. 1b). The alpha-phase content for each analysis point is given in column 3 ("Alpha wt\%"), as the sum of several alpha-bronze phases used in the Rietveld refinement. The lattice parameters of these alpha phases can vary substantially, dependent on the degree of segregation for a particular analysis point. Column 4 reports the mean lattice parameter ("Mean $a$ ") obtained from a weighted average of the individual lattice constants. TOF-ND is a phasesensitive analysis method, and therefore can not observe directly the alloying elements in the alpha phase of the copper alloy. The average lattice parameter was further analysed using Vegard's rule assuming a solid solution $\mathrm{Cu}_{1-x} \mathrm{Sn}_{x}$. The apparent Sn content (ap.Sn wt\%) in the alpha-phase is given in column 5 in weight per cent. In addition, the averaging of several alpha-phases for an analysis point allows specifying a spread of the lattice parameter distribution by its variance. The corresponding spread of the apparent Sn contents (Var.Sn wt\%) follows again from Vegard's rule. This variance is correlated to the widths of diffraction peaks as illustrated in the inserts of Fig. 9. It should be emphasised that the variation of $\mathrm{Sn}$ contents exists on a microscopic level, as a result of tin segregation, inside the gauge volume. The Sn contents in the alpha phases are generally found to be above $10 \mathrm{wt} \%$ for the 15 analysis points on the Buggenum sword. The observation of the delta phase (Delta in column 7) as 
Table 4 Results from the neutron diffraction analyses obtained at 15 positions on the Buggenum sword

\begin{tabular}{|c|c|c|c|c|c|c|c|c|c|}
\hline Loc. & $\begin{array}{l}\text { Coordinates } \\
(x ; y)(\mathrm{mm})\end{array}$ & $\begin{array}{l}\text { Alpha } \\
\text { wt } \%\end{array}$ & Mean $a(\AA)$ & $\begin{array}{l}\text { ap.Sn } \\
\text { wt\% }\end{array}$ & $\begin{array}{l}\text { Var.Sn } \\
\text { wt } \%\end{array}$ & $\begin{array}{l}\text { Delta } \\
\text { wt } \%\end{array}$ & $\begin{array}{l}\text { Total } \\
\text { Sn wt } \%\end{array}$ & $\begin{array}{l}\text { Total } \\
\text { Cu wt\% }\end{array}$ & ap. $\mathrm{Sn} / \mathrm{Cu}$ \\
\hline 1 & $3.20 ; 0$ & 100.00 & 3.6951 & 13.85 & 0.71 & 0.00 & 13.85 & 86.15 & 0.161 \\
\hline 2 & $-3.20 ; 0$ & 99.61 & 3.6894 & 12.89 & 2.40 & 0.39 & 12.97 & 87.03 & 0.149 \\
\hline 3 & $3.26 ; 0$ & 95.75 & 3.6814 & 11.54 & 7.74 & 4.25 & 12.43 & 87.57 & 0.142 \\
\hline 4 & $-3.26 ; 0$ & 98.70 & 3.6901 & 13.00 & 2.32 & 1.30 & 13.26 & 86.74 & 0.153 \\
\hline 7 & $0 ;-17.57$ & 98.40 & 3.6909 & 13.14 & 2.72 & 1.60 & 13.45 & 86.55 & 0.155 \\
\hline 5 & $0 ; 0$ & 93.90 & 3.6811 & 11.50 & 8.10 & 6.10 & 12.78 & 87.22 & 0.147 \\
\hline 6 & $0 ; 17.39$ & 97.99 & 3.6902 & 13.02 & 3.36 & 2.01 & 13.41 & 86.58 & 0.155 \\
\hline 8 & $0 ; 0$ & 99.16 & 3.6783 & 11.03 & 8.86 & 0.84 & 11.21 & 88.79 & 0.126 \\
\hline 11 & $0 ; 12.61$ & 98.17 & 3.6848 & 12.11 & 3.76 & 1.83 & 12.48 & 87.52 & 0.143 \\
\hline 9 & $0 ; 0$ & 95.83 & 3.6754 & 10.54 & 13.17 & 4.18 & 11.46 & 88.54 & 0.129 \\
\hline 10 & $0 ;-12.60$ & 98.23 & 3.6848 & 12.12 & 3.27 & 1.77 & 12.48 & 87.52 & 0.143 \\
\hline 13 & $0 ;-12.87$ & 98.84 & 3.6861 & 12.34 & 1.84 & 1.16 & 12.57 & 87.43 & 0.144 \\
\hline 12 & $0 ; 0$ & 94.78 & 3.6775 & 10.88 & 5.22 & 5.22 & 12.02 & 87.98 & 0.137 \\
\hline 14 & $0 ; 11.81$ & 99.43 & 3.6869 & 12.47 & 1.50 & 0.57 & 12.58 & 87.42 & 0.144 \\
\hline 15 & $0 ; 0$ & 95.09 & 3.6774 & 10.86 & 10.09 & 4.91 & 11.93 & 88.07 & 0.136 \\
\hline
\end{tabular}

The coordinates indicate the analysis positions in terms of depth $(x)$ and the width $(y)$, respectively, with reference to a zero-line that runs through the central figure-axis of the sword. The z-positions are shown in Fig. 1b. Weight fractions of the alpha-bronze and delta bronze phases are given in weight percent. Estimates of the $\mathrm{Sn}$ and $\mathrm{Cu}$ contents in the alpha phase are calculated using the Vegard-type $\mathrm{Cu}-\mathrm{Sn}$ calibration curve. Var.Sn denotes the range of Sn compositions, related to the broadening of the diffraction peaks

component of the (alpha + delta) eutectoid is therefore not surprising [14]. The presence of the delta phase depends on the homogenization treatment of the material (see below). From the phase fractions of alpha phases and the delta phase the total averaged Sn content ("Total Sn" in column 8) can be calculated, based on the fixed $\mathrm{Sn} / \mathrm{Cu}$ ratio (32.6 wt\% Sn) of the delta phase. The total copper content (Total $\mathrm{Cu}$ ) is then given, assuming that $\mathrm{Cu}$ and $\mathrm{Sn}$ contents add up to $100 \%$. Table 4 also lists the apparent $\mathrm{Sn} / \mathrm{Cu}$ ratios obtained from total copper and tin fractions.

The total Sn contents of the Buggenum sword vary between 11.2 and $13.8 \mathrm{wt} \%$. The values of the handle (points 1-4) are, on average, significantly higher (13.1 wt\%) compared to the blade (points 5, 8-15) $(12.1 \mathrm{wt} \%)$. The same trend is observed for the $\mathrm{Sn}$ in the alpha-phase. The rivets show a similar composition as the handle. It should be noted again that analysis points 6 and 7 measure the internal central parts of the rivets, and not the parts of the rivets visible on the surface. The delta phase varies from 0 to $6.1 \mathrm{wt} \%$ and is much more pronounced in the mid-rib of the sword, with the exception of point 8 on the mid-rib (where the delta phase is missing), and on point 3 on the handle (where it has a strong presence). With respect to the blade of the sword, the tin contents on the edge $(10,11,13,14)$ are observed slightly higher on the edge $(12.5 \mathrm{wt} \%)$ compared to the centre of the mid-rib (11.9 wt \%). This difference is not considered significant and might be due to the difficulties to fit the highly structured peaks measured in the mid-rib.
The presence of the delta phase, as manifestation of the microstructure of the alloy, is correlated to the observation of Sn segregation in the alpha phase. Figure 9 illustrates the different amounts of diffraction peak broadening on two points on the blade, one on the edge (11) and one in the midrib (9). The diffraction peaks from the mid-rib are very broad and structured, with a huge Var.Sn value of $13.2 \mathrm{wt} \%$, i.e. almost all $\mathrm{Sn}$ values between 0 and $14 \mathrm{wt} \%$ are present inside a small gauge volume. Note that $14 \mathrm{wt} \%$ is about the maximum amount of tin that an alpha phase can incorporate. The high-tin delta phase appears with the formation of the (alpha + delta) eutectic for Sn values above $10 \mathrm{wt} \%$ [14]. In contrast, the diffraction peaks on the edge of the blade are considerably sharper, i.e. indicate diminished Sn segregation, with a much reduced amount of the delta phase.

\section{Discussion and conclusions from the ND data}

The sword consists of a high-tin binary bronze, with both alpha- and delta tin-copper phases present. The total tin contents determined from TOF-ND, and not yet corrected for minor elements, vary slightly from $12 \mathrm{wt} \%$ on the blade, to $13.1 \mathrm{wt} \%$ in the hilt. The alloy shows extensive Sn segregation in the centre of the blade, along the mid-rib, accompanied by the presence of the delta phase. This observation is consistent with the formation of the (alpha + delta) eutectoid in an as-cast bronze that has not been subjected to a homogenization treatment. The alloy 
near the edge of the blade, and also the hilt, is characterized by much more well-defined Sn-contents (evidenced by sharp diffraction peaks), as typically observed for bronzes which have been partially homogenized by successive annealing and working cycles, for the purpose of hardening [12]. The homogenization and hardening of the bronze on the blade and the choice of Sn composition indicate that the sword was manufactured as a potentially functional weapon, and not necessarily as a ritual object with a sole ceremonial purpose. This conclusion is important for archaeological considerations about the Buggenum in relation to similar swords.

\section{Comparing NRCA with neutron diffraction}

The NRCA results of the blade should be compared with TOF-ND results obtained at four positions $(8,9,12,15)$ of the rib and four positions $(10,11,13,14)$ on the edge of the blade with correction of the apparent $\mathrm{Sn} / \mathrm{Cu}$ ratio for the minor elements observed by NRCA since neutron diffraction does not distinguish between tin and the other elements like $\mathrm{Sb}, \mathrm{As}, \mathrm{Ag}$, In, Co and Zn, in the solid solution. Using similar Vegard-type curves available for $\mathrm{Zn}, \mathrm{Sb}$ and As, these elements account for a lattice parameter shift of about $0.002 \AA$. A re-calculation of the Sn content of the alpha phase results in a lower value by at least $0.3 \%$ due to the minor elements. This reduces the $\mathrm{Sn} / \mathrm{Cu}$ ratio of the mid-rib to 0.129 and to 0.139 for the edges of the blade. The $\mathrm{Sn} / \mathrm{Cu}$ ratio for the blade determined by NRCA as 0.126 is close to value of the rib as determined by TOF-ND. This is reasonable since the bronze mass seen during the NRCA measurements in the circular beam spots is mainly related to the rib.

It is also possible to compare the composition of the hilt as determined by NRCA on position 1DE and by TOF-ND on the positions 1 and 2. The NRCA measurement at 1DE gives the value 0.151 for the $\mathrm{Sn} / \mathrm{Cu}$ weight ratio. The mean value of the apparent $\mathrm{Sn} / \mathrm{Cu}$ weight ratio determined by TOF-ND at positions 1 and 2 is 0.155 . This value corrected for the minor elements in the alpha-phases leads to 0.1515 . Thus the agreement between NRCA and TOF-ND results of the hilt is excellent.

A comparison between the NRCA measurement at $1 \mathrm{CF}$ and the TOF-ND measurements at positions 3 and 4 is less meaningful due to the contribution of the tongue of the blade. But both measurements show lower values for the $\mathrm{Sn} / \mathrm{Cu}$ weight ratio due to the fact that the blade has a lower ratio compared to the hilt.

\section{Activation of objects due to neutron capture}

NRCA experiments at GELINA are always performed with an overlap filter, which removes thermal neutrons from the beam, such that the intensity of thermal neutrons is reduced by a high factor. However, there will be some activity induced by resonance capture. The number of captures in resonances can be estimated from the observed number of captures divided by the detection efficiency $(\approx 20 \%)$. In the case of capture in ${ }^{63} \mathrm{Cu}$ this leads to an estimation of $750 \mathrm{~Bq}$ for ${ }^{64} \mathrm{Cu}\left(t_{1 / 2}=12.7 \mathrm{~h}\right)$ directly after the measurements neglecting decay during the measurements, or a specific activity of $5 \mathrm{~Bq} / \mathrm{g}$ for the parts of the Buggenum sword that have been in the beam. The $5.1 \mathrm{~min}$ activity due to capture in ${ }^{65} \mathrm{Cu}$ is also not a problem; most of it will be decayed during the experiments.

Similar estimates can be made for other long-living activities induced by resonance capture in $\mathrm{Sn}$ and the minor elements. All activities are much lower than official limits (some of them are given Table 5) below which an object is not considered to be radioactive. Hence, in case of NRCA experiments at GELINA the remaining activity is expected to be negligible as was already pointed out by Blaauw et al. [15] and Postma and Schillebeeckx [2].

Since the TOF-ND experiments depend on the use of sub-thermal neutrons, activation of the object should be considered with care. The main activity is expected from ${ }^{64} \mathrm{Cu}\left(t_{1 / 2}=12.7 \mathrm{~h}\right)$ and some other long-living isotopes may be of concern. The most important long-living activities are quoted in Table 5, that is, specific activities in $\mathrm{Bq} / \mathrm{g} 1 \mathrm{~h}$ after the runs at ENGIN-X and 1 week later. Total amounts of activities in the irradiated $36 \mathrm{~g}$ of the sword (total weight $920 \mathrm{~g}$ ) after 1 week of storage are presented. Internationally accepted limits for specific and total activations, below which the object is not considered to be a radioactive object anymore, are quoted in columns 5 and 7 of Table 5. It is clear from this table that a waiting period of 1 week after the diffraction measurements was sufficient to return the Buggenum sword with negligible radioactivity to its owner.

It is common practise of both institutes to monitor objects for remaining radioactivity to a very low level before objects are returned to their owners.

Table 5 Activation of the Buggenum sword at ENGIN-X

\begin{tabular}{|c|c|c|c|c|c|c|}
\hline \multirow[t]{2}{*}{ Isotope } & \multirow{2}{*}{$\begin{array}{l}\text { Half } \\
\text { life }\end{array}$} & \multicolumn{2}{|l|}{$\mathrm{Bq} / \mathrm{g}$} & \multirow{2}{*}{$\begin{array}{l}\mathrm{Bq} / \mathrm{g} \\
\text { limit }\end{array}$} & \multirow{2}{*}{$\begin{array}{l}\mathrm{Bq} \\
36 \mathrm{~g}\end{array}$} & \multirow{2}{*}{$\begin{array}{l}\mathrm{Bq} \\
\text { limit }\end{array}$} \\
\hline & & $\begin{array}{l}\text { After } \\
1 \mathrm{~h}\end{array}$ & $\begin{array}{l}\text { After } \\
1 \text { week }\end{array}$ & & & \\
\hline${ }^{64} \mathrm{Cu}$ & $12.7 \mathrm{~h}$ & $1.0 \mathrm{e}+5$ & 11.0 & 100 & 400 & $1 e+6$ \\
\hline${ }^{113} \mathrm{Sn}$ & $115 \mathrm{~d}$ & 0.106 & 0.102 & 1000 & 3.7 & $1 e+7$ \\
\hline${ }^{117 m^{m}} \mathrm{Sn}$ & $14 \mathrm{~d}$ & 0.070 & 0.051 & 100 & 1.8 & $1 e+6$ \\
\hline${ }^{122} \mathrm{Sb}$ & $2.68 \mathrm{~d}$ & 26.7 & 4.41 & 100 & 160 & $1 e+4$ \\
\hline${ }^{124} \mathrm{Sb}$ & $60.2 \mathrm{~d}$ & 0.62 & 0.57 & 10 & 20 & $1 e+6$ \\
\hline${ }^{110 m} \mathrm{Ag}$ & $249 \mathrm{~d}$ & 0.099 & 0.097 & 10 & 3.5 & $1 e+6$ \\
\hline${ }^{60} \mathrm{Co}$ & $5.27 \mathrm{y}$ & 0.128 & 0.128 & 1 & 4.6 & $1 e+5$ \\
\hline
\end{tabular}




\section{General conclusions}

Both the NRCA and TOF-ND experiments show that the hilt and blade of the Buggenum sword are different casts. The $\mathrm{Sn} / \mathrm{Cu}$ ratios obtained by both methods are in good agreement. The amounts of $\mathrm{Sn}, \mathrm{Sb}, \mathrm{As}, \mathrm{Ag}$ and In are basically constant over the length of the blade, with at most a small variation of $\mathrm{Sn}$. At the edges the Sn contents differ slightly from the mid-rib of the blade. The tin content is sufficiently large (between about 7 and $13 \mathrm{wt} \%$ ) to homogenize and harden the edges by hammering and annealing. Although the absence of wear and traces of use indicates that the Buggenum sword may have functioned as a ritual object, it is evident from the results presented in this paper that it was manufactured as a potentially functional weapon.

Acknowledgements We like to thank J.C. Drohe, R. Wynants and J. Van Gils for their technical support during the measurements at the GELINA facility of IRMM, in Geel (B). We are very grateful for the loan of the Buggenum sword from the National Museum of Antiquities in Leiden (NL) and we like to sincerely thank Steph Scholten (NMA) for his interest in this project. We thank E. Godfrey for valuable discussions on the interpretation of the diffraction analysis results. This study has been financial supported and carried out as part of the EU FP6 Ancient Charm project, funded by the European Commission under the contract no. 15311.

\section{References}

1. Postma H, Blaauw M, Bode P, Mutti P, Corvi F, Siegler P (2001) Neutron-resonance capture analysis of materials. J Radioanal Nucl Chem 248:115-120

2. Postma H, Schillebeeckx P (in press) Neutron resonance capture and transmission analysis. Encyclopedia of analytical chemistry

3. Kockelmann W, Siano S, Bartoli L, Visser D, Hallebeek P, Traum R, Linke R, Schreiner M, Kirfel A (2006) Applications of
TOF neutron diffraction in archaeometry. Appl Phys A 83: 175-182

4. von Quillfeldt I (1995) Die Vollgriffschwerter in Süddeutschland, Prähistorische Bronzefunde, Abteilung IV, band 11. Franz Steiner Verlag Stuttgart

5. Butler JJ, Fontijn DR (2007) Spiralling from the Danube to the Meuse: the metal-hilted sword from Buggenum (Netherlands, Limburg). In: Burgess Ch, Topping P, Lynch F (eds) BEYOND STONEHENGE, Essays in the bronze age in the honour of Colin Burgess. Oxford Books, pp 301-315

6. Mondelaers W, Schillebeeckx P (2006) GELINA, a neutron timeof-flight facility for high-resolution neutron data measurements. Notiziario Neutroni e Luce di Sincrotrone 11(2):19-25

7. Sage C, Berthoumieux E, Bouland O, Gunsing F, Plomben AJM, Schillebeeckx P, Siegler P, van Opstal N, Wynants R (2007) A new high efficiency array of $\mathrm{C}_{6} \mathrm{D}_{6}$ detectors for capture cross section measurements at GELINA. In: International conference on nuclear data for science and technology, pp 583-586

8. Briesmeister J (2000) MCNP_a general Monte Carlo N-particle transport code-Version 4C2, LA-13709-M

9. Santisteban JR, Daymond MR, James JA, Edwards L (2006) ENGIN-X: a third-generation neutron strain scanner. J Appl Cryst 39:812-825

10. James JA, Santisteban JR, Daymond MR, Edwards L (2004) A virtual laboratory for neutron and synchrotron strain scanning. Physica B 350:E743-E746

11. Larson AC, von Dreele RB (2004) General structure analysis system. Los Alamos National Laboratory Report LAUR 86-748

12. Moedlinger M (2007) Eine vertiefende Studie zur mittelbronzeund urnenfelderzeitlichen Bewaffnung und Sozialstruktur. PhD thesis, Fachbereich Ur- und Frühgeschichte, University of Vienna (Austria)

13. Vegard L (1921) Die Konstitution der Mischkristalle und die Raumfüllung der Atome. Zeitschrift für Physik 5:17-26

14. Siano S, Bartoli L, Zoppi M, Kockelmann W, Daymond M, Dann JA, Garagnani MG, Miccio M (2003) Microstructural bronze characterisation by time of flight neutron diffraction. In: Proc. archaeometallurgy in Europe, vol 2, pp 319-329

15. Blaauw M, Postma H, Mutti P (2005) An attempt to date an antique Benin bronze using neutron resonance capture analysis. Appl Radiat Isot 62:429-433 